ARTÍCULO DE REVISIÓN

\title{
FISIOLOGÍA DE LA GLÁNDULA TIROIDES. DISFUNCIÓN Y PARÁMETROS FUNCIONALES DE LABORATORIO EN PATOLOGÍA DE TIROIDES
}

\section{Thyroid Physiology. Disfunction and Laboratory Tests in Thyroid Diseases}

\author{
Luis Francisco SANTIAGO-PEÑA \\ Complejo Asistencial Universitario de Zamora. Sección de Endocrinología y Nutrición. Zamora. España \\ Correspondencia: lsantiago@saludcastillayleon.es
}

Fecha de recepción: 28 de septiembre de 2019

Fecha de aceptación: 23 de diciembre de 2019

Fecha de publicación: 26 de diciembre de 2019

Fecha de publicación del fascículo: 1 de septiembre de 2020

Conflicto de intereses: Los autores declaran no tener conflictos de intereses

Imágenes: Los autores declaran haber obtenido las imágenes con el permiso de los pacientes

Política de derechos y autoarchivo: se permite el autoarchivo de la versión post-print (SHERPA/RoMEO)

Licencia CC BY-NC-ND. Licencia Creative Commons Atribución-NoComercial-SinDerivar 4.0 Internacional

Universidad de Salamanca. Su comercialización está sujeta al permiso del editor

RESUMEN: El estudio de la patología funcional tiroidea requiere de un adecuado conocimiento de los procesos implicados en la síntesis, secreción, transporte, metabolismo y regulación y mecanismo de acción de las hormonas tiroideas En el manejo inicial de la disfunción tiroidea, la interpretación de los valores de Tirotropina (TSH) y de las hormonas periféricas (T4 y T3 libre) nos permitirán saber si la etiología está en el tiroides o fuera del tiroides. Objetivo: exponer unos conocimientos básicos sobre la fisiología y las alteraciones funcionales de la glándula tiroides.

PALABRAS CLAVE: test de función tiroidea; tirotropina; metabolismo hormona tiroidea; receptor de hormona tiroidea; tiroxina; triiodotironina.

SUMMARY: The study of functional thyroid pathology requires an adequate knowledge of the processes involved in the synthesis, secretion, transport, metabolism and regulation and mechanism of action of thyroid hormones In the initial management of thyroid dysfunction, the interpretation of the values of Thyrotropin (TSH) and peripheral hormones (free T4 and T3) will let us know if the etiology is in the thyroid or outside the thyroid. Objective: to expose some basic knowledge about the physiology and functional alterations of the thyroid gland.

KEYWORDS: thyroid function tests; thyrotropin; thyroid hormone metabolism; thyroid hormone receptor; thyroxine; triiodothyronine. 


\section{FISIOLOGÍA DE LA GLÁNDULA TIROIDES. DISFUNCIÓN Y PARÁMETROS FUNCIONALES DE LABORATORIO EN PATOLOGÍA DE TIROIDES \\ SANTIAGO-PEÑA L F}

\section{INTRODUCCIÓN}

La función de la glándula tiroides es producir la cantidad de hormona tiroidea necesaria para satisfacer las necesidades de los tejidos periféricos [1]. Las hormonas tiroideas actúan en casi todos los tejidos del organismo a nivel nuclear. Para que se produzca la acción de las hormonas tiroideas es necesario que todo el proceso de síntesis, metabolismo, regulación y unión de las hormonas tiroideas con su receptor, se haga de manera adecuada. En este capítulo revisaremos cada uno de los aspectos anteriores.

\section{SÍNTESIS DE LAS HORMONAS TIROIDEAS}

La síntesis de hormonas tiroideas, que se produce en la célula folicular tiroidea, requiere de un aporte de yodo y la síntesis de una proteína, que tiene en su estructura primaria, aminoácidos Tirosina, la tiroglobulina (Tg).

Las hormonas tiroideas son sintetizadas siguiendo las siguientes etapas:

1. Transporte de yoduro(I-): La célula folicular tiroidea capta yoduro sódico a través del cotransportador de yodo sodio (NIS) situado en la membrana basolateral. Este yoduro difunde por la célula hasta la membrana apical, donde es transportado, por la pendrina (transportador yodo-cloro), a las vesículas que se fusionan con la membrana apical.

2. En estas vesículas, el yoduro es oxidado a yodo por acción de la enzima peroxidasa tiroidea (TPO) para su posterior unión a los residuos de tirosina (aproximadamente $10 \%$ de los residuos de tirosina de la cadena de tiroglobulina, dando lugar a monoyodotirosinas (MIT) y diyodotirosinas (DIT) (organificación) [2]

3. Acoplamiento de residuos yodados: La unión de dos residuos de DIT da lugar a T4 (tiroxina) y de un residuo de MIT con otro de DIT a Triyodotironina (T3). Este acoplamiento es catalizado por la TPO.

Ediciones Universidad de Salamanca / @®@
4. Síntesis de Tiroglobulina: Se produce en el retículo endoplásmico rugoso de la célula folicular tiroidea y es incorporada a las vesículas en el polo apical de la célula para la posterior yodación de algunos residuos de tirosina. En el interior de la Tg hay T4, T3 MIT, DIT y residuos de tirosina sin yodar.

5. Liberación de hormonas tiroideas: Las vesículas con $\mathrm{Tg}$ se fusionan a la membrana apical y se internalizan por micropinocitosis. Estas vesículas se unen a los lisosomas, formando fagolisosomas, donde, por acción de enzimas líticas, se libera T4, T3, MIT, DIT. Las hormonas T4 y T3 son liberadas al torrente sanguíneo. MIT y DIT son degradadas en el interior de la célula folicular y reutilizado su yodo.

Estas cinco etapas son estimuladas por la hormona Tirotropina (TSH) segregada en las células tirotropas de la hipófisis.

En el tiroides se produce el $100 \%$ de la T4 circulante y el $20 \%$ de la T3 circulante.

\section{TRANSPORTE DE LAS HORMONAS TIROIDEAS}

En el plasma, la T4 y la T3 se encuentran de dos formas, unidas a proteínas y libres. Más del 99,95 \% de la T4 y más del 99,5 \% de la T3 están unidas a las proteínas transportadoras. Estas proteínas son la globulina transportadora de tiroxina (TBG en inglés), la transtirretina, la albúmina y las lipoproteínas.

La T4 se une en un $75 \%$ TBG, $12 \%$ a albúmina, $10 \%$ a transtirretina y $3 \%$ a lipoproteínas, aproximadamente, quedando un $0,02 \%$ aproximadamente circulando en forma libre.

La T3 se une en un $80 \%$ a TBG; $15 \%$ a albúmina y lipoproteinas, $5 \%$ a transtirretina, aproximadamente, quedando un $0,5 \%$ aproximadamente circulando en forma libre.

Las proteínas transportadoras permiten mantener la concentración de hormona libre en u estrecho margen, asegurando un continuo y permanente aporte de hormona a las células diana [2]. 


\section{FISIOLOGÍA DE LA GLÁNDULA TIROIDES. DISFUNCIÓN Y PARÁMETROS FUNCIONALES DE LABORATORIO EN PATOLOGÍA DE TIROIDES \\ SANTIAGO-PEÑA L F}

La hormona libre es la que entra en la célula diana para su posterior unión con el receptor.

\section{REGULACIÓN DE LAS HORMONAS TIROIDEAS}

La tirotropina (TSH) secretada en la adenohipófisis es la principal reguladora de la función tiroidea.

\section{METABOLISMO DE HORMONAS TIROIDEAS}

La tasa fraccional de recambio metabólico de la T4 es de aproximadamente un $10 \%$ por día (vida media de 6,7 días) y de la T3 de un $60 \%$ (vida media de 0,75 días) [1].

La vía más importante para el metabolismo de la T4 es la monodesyodización del anillo externo para transformarse en T3. Esta reacción es catalizada por desyodinasa tipo 1(D1) y tipo 2 (D2). La desyodinasa tipo 3(D3) cataliza la desyodación del anillo interno (5) de T4 convirtiéndola en T3 inversa (rT3), la forma inactiva de la hormona tiroidea.

La D1 predomina en hígado, riñón y tiroides; es sensible a propiltiouracilo (PTU); da origen a T3 plasmática (sobre todo en pacientes hipertiroideos) y degrada la rT3. La D2 predomina en músculo, cerebro, hipófisis, placenta y piel; proporciona T3 intraceluar en tejidos específicos y da origen a T3 plasmática. La D3 tiene amplia distribución corporal e inactiva la T3 y T4.

La T4 también se inactivan vía glucoronidación (eliminación biliar) y sulfuración.

\section{MECANISMO DE ACCIÓN}

Las hormonas tiroideas entran en la célula por difusión y a través de transportadores en el algunos tejidos [3]. Varias proteínas con especificidad cruzada tienen capacidad para transportar hormonas tiroideas a través de las membranas celulares, incluyendo entre ellas el transportador de monocarboxilatos (MCT en inglés), que es transportador específico de hormona tiroidea y tiene especial relevancia para el aporte de hormonas tiroideas al cerebro a través de la barrera hematoencefálica [4].

Para la acción fisiológica de la hormona tiroidea, T3, se requiere de biodisponibilidad de T3 a nivel del núcleo, de receptores nucleares de hormonas tiroides (RT), de cofactores de receptor y de elementos de reguladores de DNA.

Hay 2 tipos de RT, estructuralmente similares, RT alfa y RT beta, con distintas isoformas, RT alfa 1, RT alfa 2, RT beta 1, RT beta 2 y RT beta 3 .

El RT forma un heterodímero con el receptor $\mathrm{X}$ retinoide (RXR). Cuando se une la T3 a este complejo se desplaza el correpresor del receptor y se acopla un coactivador del receptor, permitiendo la unión del complejo a una secuencias específicas de ADN, dando lugar a la transcripción de mRNA.

\section{REGULACIÓN DE LA FUNCIÓN TIROIDEA}

La tirotropina (TSH) es el principal regulador de los estados morfológicos y funcionales del tiroides. Las hormonas tiroideas median la regulación por retroalimentación de la secreción de TSH y la triptorelina (TRH) secretada en el hipotálamo determina su punto de ajuste.

La concentración de TSH guarda una relación logarítmica/lineal con la concentración de tiroxina libre (T4L).

\section{MANEJO DE LABORATORIO DE LA FUNCIÓN TIROIDEA}

La función del tiroides puede ser valorada por la determinación de TSH o/y de T4L (en ocasiones T3L).

Determinación de TSH: Es la principal prueba para la evaluación de la función tiroidea y de la integridad del eje hipotálamo hipofisario tiroideo.

Actualmente se usan ensayos quimioluminométricos de $3^{\text {a }}$ generación con límite de detección de 0,01 mU/L. En la mayoría de los ensayos de 


\section{FISIOLOGÍA DE LA GLÁNDULA TIROIDES. DISFUNCIÓN Y PARÁMETROS FUNCIONALES DE LABORATORIO EN PATOLOGÍA DE TIROIDES \\ SANTIAGO-PEÑA L F}

laboratorios, los límites se sitúan entre 0,4-4,2 $\mathrm{mU} / \mathrm{L}$.

Los niveles de TSH deben ser valorados con precaución en pacientes hospitalizados, a menos que los valores se sitúen por debajo de 0,1 o por encima de $20 \mathrm{mU} / \mathrm{L}[6]$.

El límite superior de normalidad es edad dependiente, hallándose en algunos estudios poblaciones que el percentil 97,5 en mayores de 80 años se situaba en 7,49 mU/L (mientras que en el rango de edad de 20-29 años, se situaba en 3,56 mU/L) [5].

Determinación de tiroxina libre y triyodotironina: Las determinaciones más exactas de la concentración de T4L y T3L se consigue mediante análisis en un dializado o ultrafiltrado de suero Estos métodos no son prácticos desde el punto de vista clínico, por lo que se recurre a métodos automatizados de cuantificación de la T4L o/y T3L.

Los ensayos de $3^{\text {a }}$ generación de TSH son los más sensibles y específicos para el despistaje de función tiroidea en población ambulatoria. Hay 3 situaciones en la que le determinación, aislada, de TSH no sería útil para valorar función tiroidea: en pacientes con patología hipotálamo-hipofisaria conocida o sospechada, en pacientes hospitalizados y en pacientes con fármacos que alteran la secreción de TSH (ej.: dopamina, altas dosis de glucocorticoides, metoclopramida, análogos de somatostatina).

\section{PATRONES DE FUNCIÓN O DISFUNCIÓN TIROIDEA}

En la Tabla 1 se reflejan las situaciones de función clínica más frecuentes. Una vez realizado el diagnóstico bioquímico, deberían realizarse otros test de laboratorio y pruebas de imagen funcional para establecer el diagnóstico etiológico de la patología tiroidea o extratiroidea que afecta al tiroides. A parte de los patrones descritos en la tabla, puede darse otros de más difícil interpretación y que pueden estar en relación con situaciones de tránsito de hiper o hipofunción a normofunción por efecto de los tratamientos.
Tabla 1: Patrones hormonales de función tiroidea.

\begin{tabular}{|l|l|l|l|}
\hline $\begin{array}{l}\text { TSH } \\
\text { sérica }\end{array}$ & $\begin{array}{l}\text { T4L } \\
\text { sérica }\end{array}$ & $\begin{array}{l}\text { T3L } \\
\text { sérica }\end{array}$ & Valoración \\
\hline Función hipotálamo-hipofisaria normal \\
\hline Normal & Normal & Normal & Eutiroidismo \\
\hline Baja & $\begin{array}{l}\text { Alta o } \\
\text { Normal }\end{array}$ & Alta & $\begin{array}{l}\text { Hipertiroidismo } \\
\text { primario }\end{array}$ \\
\hline Baja & Normal & Normal & $\begin{array}{l}\text { Hipertiroiddismo } \\
\text { subclínico }\end{array}$ \\
\hline Alta & Normal & Normal & $\begin{array}{l}\text { Hipotiroidismo } \\
\text { subclínico }\end{array}$ \\
\hline Alta & Baja & $\begin{array}{l}\text { Baja o } \\
\text { Normal }\end{array}$ & $\begin{array}{l}\text { Hipotiroidismo } \\
\text { primario }\end{array}$ \\
\hline Alta & Alta & Alta & $\begin{array}{l}\text { Resistencia a } \\
\text { hormonas tiroideas }\end{array}$ \\
\hline \multicolumn{2}{|l|}{ Función hipotálamo-hipofisaria alterada } \\
\hline $\begin{array}{l}\text { Normal o } \\
\text { Alta }\end{array}$ & Alta & Alta & $\begin{array}{l}\text { Hipertiroidismo } \\
\text { secundario (TSH } \\
\text { dependiente) }\end{array}$ \\
\hline $\begin{array}{l}\text { Baja o } \\
\text { Normal }\end{array}$ & Baja & Baja & $\begin{array}{l}\text { Hipotiroidismo } \\
\text { central }\end{array}$ \\
\hline
\end{tabular}

\section{CONCLUSIONES}

Para una adecuada valoración de la función tiroidea es conveniente conocer la síntesis y metabolismo de las hormonas tiroideas, así como el sistema de retroalimentación del eje hipotálamo hipofisario tiroideo. Para la interpretación de los valores analíticos de TSH y hormonas periféricos, se requiere valorar tratamientos y enfermedades intercurrentes que puedan interferir en la secreción de TSH y en el metabolismo de las hormonas tiroideas.

\section{BIBLIOGRAFÍA}

1. Larsen PR, Davies TF, Schlumberger MJ, Hay ID. Fisiología del troides y evaluación diagnóstica de los pacientes con trastornos tiroideos. En Kronenber MD, Melmed S, Polonsky KS, Larsen PR editories. Williams Tratado de Endocrinologia Edicion 11. 2009 p. 305-40. 


\section{FISIOLOGÍA DE LA GLÁNDULA TIROIDES. DISFUNCIÓN Y PARÁMETROS FUNCIONALES DE LABORATORIO EN PATOLOGÍA DE TIROIDES \\ SANTIAGO-PEÑA L F}

2. Douglas SR. Thyroid hormone synthesis and physiology. En Cooper DS, Mulder JE, Editors. Uptodate: 2019. Disponible en https://www.uptodate.com. Consultado el 01/09/2019.

3. Hennemann G, Docter R, Friesema EC, de Jong M, Krenning EP, Visser TJ. Plasma membrane transport of thyroid hormones and its role in thyroid hormone metabolism and bioavailability. Endocr Rev. 2001; 22(4):451-76.

4. Bernal J, Guadaño-Ferraz A, Morte B. Thyroid hormone transporters-functions and clinical implications [published correction appears in
Nat Rev Endocrinol. 2015 Sep;11(9):506] [published correction appears in Nat Rev Endocrinol. 2015;11(12):690]. Nat Rev Endocrinol. 2015; 11(7):406-17.

5. Surks MI, Hollowell JG. Age-specific distribution of serum thyrotropin and antithyroid antibodies in the US population: implications for the prevalence of subclinical hypothyroidism. JClinEndocrinol Metab. 2007; 92(12):4575-82.

6. Dufour DR. Laboratory tests of thyroid function: uses and limitations. Endocrinol Metab Clin North Am. 2007; 36(3):579-94. 